\title{
A novel SPAST gene mutation identified in a Chinese family with hereditary spastic paraplegia
}

\author{
Weiwei Yu \\ Peking University First Hospital \\ Haiqiang Jin \\ Peking University First Hospital \\ Jianwen Deng \\ Peking University First Hospital \\ Ding Nan \\ Peking University First Hospital \\ Yining Huang ( $\square$ ynhuang@bjmu.edu.cn ) \\ Peking University First Hospital https://orcid.org/0000-0002-1657-4151
}

\section{Research article}

Keywords: Hereditary spastic paraplegia, gait disorder, Whole Exome Sequencing, SPAST gene, in-frame deletion

Posted Date: May 19th, 2020

DOI: https://doi.org/10.21203/rs.3.rs-26296/v2

License: (c) (1) This work is licensed under a Creative Commons Attribution 4.0 International License.

Read Full License

Version of Record: A version of this preprint was published at BMC Medical Genetics on June 3rd, 2020. See the published version at https://doi.org/10.1186/s12881-020-01053-7. 


\section{Abstract}

Background: Hereditary spastic paraplegia is a heterogeneous group of clinically and genetically neurodegenerative diseases characterized by progressive gait disorder. Hereditary spastic paraplegia can be inherited in various ways, and all modes of inheritance are associated with multiple genes or loci. At present, more than 76 disease-causing loci have been identified in hereditary spastic paraplegia patients. Here, we report a novel mutation in SPAST gene associated with hereditary spastic paraplegia in a Chinese family, further enriching the hereditary spastic paraplegia spectrum.

Methods: Whole genomic DNA was extracted from peripheral blood of the 15 subjects from a Chinese family using DNA Isolation Kit. The Whole Exome Sequencing of the proband was analyzed and the result was identified in the rest individuals. RaptorX prediction tool and Protein Variation Effect Analyzer were used to predict the effects of the mutation on protein tertiary structure and function.

Results: Spastic paraplegia has been inherited across at least four generations in this family, during which only four HSP patients were alive. The results obtained by analyzing the Whole Exome Sequencing of the proband exhibited a novel disease-associated in-frame deletion in the SPAST gene, and the this mutation also existed in the rest three HSP patients in this family. This in-frame deletion consists of three nucleotides deletion (c.1710_1712delGAA) within the exon 16, resulting in lysine deficiency at the position 570 of the protein (p.K570del). This novel mutation was also predicted to result in the synthesis of misfolded SPAST protein and have the deleterious effect on the function of SPAST protein.

Conclusion: In this case, we reported a novel mutation in the known SPAST gene that segregated with HSP disease, which can be inherited in each generation. Simultaneously, this novel discovery significantly enriches the mutation spectrum, which provides an opportunity for further investigation of genetic pathogenesis of HSP.

\section{Background}

Hereditary spastic paraplegia (HSP), also called familial spastic paraparesis or Strü mpell-Lorrain disease, is a group of neurodegenerative and inherited heterogeneous neurological disorders characterized by a length-dependent distal axonal degeneration of the corticospinal tracts[1]. The progressive spasticity and pyramidal signs of the lower limbs are the prominent features of HSP, which can be well explained by the fact that the innervated function of the longest fibers toward to the lower extremity is prone to be affected[2].

According to whether accompanied by additional neurological or psychiatric symptoms such as ataxia, mental and cognitive changes, extrapyramidal signs, visual dysfunction or epilepsy, or with extra neurological signs, the diseases can be categorized into either pure HSP (pHSP) or complicated HSP (cHSP) $[3,4]$. The onset age of HSP exhibits a wide range from childhood to over 70 years old depending on the underlying genetic defect, even in the family with a same mutation[5]. Therefore, it is hard to explain the interaction between the genotype and the phenotype of HSP. 
Based on the distinguishably inherited trait, HSP can be classified into as autosomal dominant, autosomal recessive, X-linked, mitochondrial, or de novo[6]. Meanwhile, autosomal dominant HSP is the most common mode that accounts for approximately $70 \%$ of all HSP patients[7]. All modes of inheritance are associated with multiple genes or loci. Until now, there have been at least 76 spastic paraplegia associated with loci and more than 59 corresponding spastic paraplegia genes (SPG) have been identified[8]. The SPG4/ SPAST gene comprising 17 exons, identified as the 90-kb genomic region on chromosome 2 (2p22.3)[9], has been reported to be the most frequent cause of HSP and accounts for approximately $40 \%$ of pure autosomal dominant HSP and $10 \%$ of sporadic cases[10,11]. Over 500 mutations have been identified in the SPAST gene. Generally, SPAST gene mutations have a tendency to cause pure HSP[12] and are more common in males than females[5]. Here, we report a novel SPAST gene mutation site (c.1710_1712delGAA) that presented in a Chinese family with HSP, significantly enriching the mutation spectrum of HSP gene.

\section{Methods}

\section{Subjects}

In this study, we recruited 15 subjects (female: male ratio is about 1:1; age range: $3-63$ years) in total from a Chinese family with HSP. This family was enrolled in our study on the basis of the following criteria: (1) Based on Harding's criteria[4], the proband, a 63-years-old female, was diagnosed with HSP; (2) The family of the proband had at least four affected relatives with HSP; (3) The family was potentially informative for designing a study to investigate the genetic mutations. Total of 15 individuals were performed with neurologic examination, four of which had the same clinical manifestations and the rest were all asymptomatic. The study was conducted according to the Declaration of Helsinki and was authorized by the Ethics Committee of Peking University First Hospital. The related written informed consents for publishing the case details and clinical images in medical journals were obtained from all the participants and the legal guardian of the patient aged eleven years in our study.

\section{DNA extraction}

Whole genomic DNA was extracted from peripheral blood of the 15 family members using DNA Isolation Kit (Bioteke, AU1802) as previously described[13]. Concentrations of each DNA sample were measured on a Qubit fluorometer (Invitrogen, Q33216) using Qubit dsDNA HS Assay Kit (Invitrogen, Q32851). Meanwhile, $1 \%$ agarose gel electrophoresis was performed for quality control of each DNA sample.

\section{Libraries preparation and amplification}

DNA libraries were prepared with KAPA Library Preparation Kit (Kapa Biosystems, KR0453) following the manufacturer's instructions, which mainly contains three major procedures: end-repair of fragmented DNA, A-tailing, adapter ligation and amplification [14]. Purifications between procedures were achieved using Agencourt AMPure XP beads. After the ligation reaction with beads, $50 \mu$ ligation was totally resuspend in $45 \mu \mathrm{IPEG} / \mathrm{NaCl}$ SPRI ${ }^{\circ}$ Solution and then incubated at $37^{\circ} \mathrm{C}$ for $2 \mathrm{~min}$. Subsequently, the 
captured beads via a magnet were incubated until the liquid is clear. The beads were washed for three times using $200 \mu \mathrm{l} 80 \%$ ethanol after discarding the clear supernatant and then was dried at room temperature (RT). Eventually, the beads captured on a magnet were thoroughly resuspended in $25 \mu \mathrm{l}$ water and incubated for 2 min at RT until the liquid was clear to be proceed with library amplification.

Libraries amplification was fulfilled by polymerase chain reaction (PCR) under the following $25 \mu \mathrm{l}$ reaction system: $12.5 \mu \mathrm{l} 2 \times$ KAPA HiFi HotStart ReadyMix, $1 \mu \mathrm{l} 5 \mu \mathrm{M}$ each primer, $10 \mu \mathrm{l}$ captured library beads suspension and $1.5 \mu \mathrm{l}$ water. PCR amplification program was set up: $98^{\circ} \mathrm{C} 2 \mathrm{~min} ; 98^{\circ} \mathrm{C} 30 \mathrm{~s} ; 65^{\circ} \mathrm{C} 30 \mathrm{~s}$; $72^{\circ} \mathrm{C} 30 \mathrm{~s}, 13$ cycles; and a final step at $72^{\circ} \mathrm{C}$ for 4 min. Subsequently, repeat the steps of washing and resuspending the beads as described above. The amplified libraries that were prepared for array capture were assessed with Qubit dsDNA HS Assay kit (Invitrogen, Q32851).

\section{Array capture and sequencing}

Pooled libraries were hybridized to the capture probes and the non-hybridized library molecules were removed via the Agilent SureSelectXT2 Target Enrichment System. Array hybridization was captured by mixing the pooled libraries with a buffer solution and oligo-blockers, which was incubated for 24 hours at $65^{\circ} \mathrm{C}$. The hybridized library molecules were performed with Dynabeads ${ }^{\circledR}$ MyOne ${ }^{\mathrm{TM}}$ Streptavidin T1 (Invitrogen, \#65601). The captured library was amplified as following: $21 \mu \mathrm{l} 2 \times \mathrm{KAPA} \mathrm{HiFi} \mathrm{HotStart}$ ReadyMix , $1 \mu \mathrm{l} 5 \mu \mathrm{M}$ primer, $20 \mu \mathrm{l}$ captured library beads suspension. PCR amplification program was $98^{\circ} \mathrm{C} 2 \mathrm{~min} ; 98^{\circ} \mathrm{C} 30 \mathrm{~s} ; 65^{\circ} \mathrm{C} 30 \mathrm{~s} ; 72^{\circ} \mathrm{C} 30 \mathrm{~s}, 13$ cycles and a final step at $72^{\circ} \mathrm{C}$ for 4 min. Purifications between procedures were conducted using Agencourt AMPure XP beads and the libraries were evaluated with Qubit dsDNA HS Assay kit (Invitrogen, Q32851). Finally, DNA libraries of the proband were analyzed by whole exome sequencing (WES). WES was carried out on the HiSeq2500 platform as paired-end 200bp reads. Illumina Sequence Control Software (SCS) was used to evaluate the sequencing data, thus removing adapter sequences in the raw data and discarding low-quality sequencing reads. Conventional Sanger sequencing of the SPAST gene was further performed in 15 individuals from the Chinese family.

\section{In-silico predictions}

Effects of the novel mutation on SPAST tertiary structure were predicted by RaptorX prediction tool[15]. Additionally, PROVEAN (Protein Variation Effect Analyzer)[16], a new algorithm, is also adopted to predict whether the mutation has an functional impact on the SPAST protein sequence variations.

\section{Results}

\section{Clinical characteristics}

The proband (II:2) (Fig.1A) , a 63-years-old female, presented to the outpatient clinic in our hospital due to her progressive difficulty walking caused by moderate spasticity of the lower limbs for 24 years. She has felt unknown gait disorder as early as in 1992. For the last 11 years, this gait disorder has gotten worse, especially in cold weather. And she was confined to a wheelchair at the age of 52 . In the last year, the 
proband suffered from the frequently urged to urinating and bowel functions. Physical examination showed that she had brisk deep tendon reflexes in all four limbs, simultaneously accompanied with obvious corticospinal tract signs (Babinski's signs was positive), and decreased sense of pain, light touch and vibration in the lower limbs characterized with stocking pattern-distributed sensory loss. Muscle strength of the upper limbs was normal, while both the extensors and flexors in the lower limbs were $3 / 5$. The results obtained from routine laboratory tests, electromyography, cranial and cervical MRIs did not reveal any obvious pathognomonic alteration. For her previous history, the proband had ever received some treatment on rheumatoid arthritis because of the pain in both hips and knees 26 years ago, but the uncomfortable symptom was not getting better. 9 years ago, a traumatic injury on her back further aggravated her discomfort though the cranial and cervical MRIs were both normal at that time.

With regard to the proband's family history (Fig.1A), her parents were deceased, but her father had similar symptoms. In addition, she had three brothers and two sisters. One of her brothers who had similar symptoms has passed away and the rest were all asymptomatic. Details about her symptomatic father and brother are not clear. Physical examination gave the below results. 叉: 9 aged 32 years had an

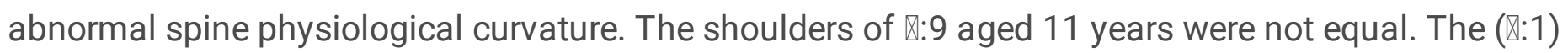
aged 46 years, 邓:9 and $: 9$ showed brisk deep tendon reflexes in all four limbs and positive Babinski signs. All the three symptomatic patients all could not run and squat since young age. Despite their motor

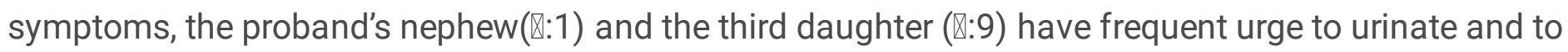
have bowel functions at the age of 40 years and 27 years.

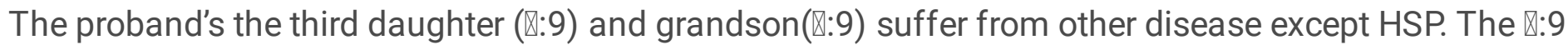
patient who was diagnosed with pulmonary hypertension has been suffering from chest tightness and shortness of breath for three years, losing the ability to work. Similarly, the echocardiography of $₫: 9$ aged eleven years showed mild reflux at mitral valve and tricuspid valve.

Clinical features of the four affected individuals in the family have been summarized in Table 1, and their clinical commonalities and personalities are exhibited respectively. The four symptomatic patients have the different degrees of disability. The disability score was evaluated according to a four-point scale (1: normal, 2: able to walk but not run, 3: need the help of a walking aid or support, 4: walk on wheelchair) [17]. In addition, the onset age ranges from 3 to 30 years old, although they have the same mutation in the exon 16.

\section{Genetic findings and prediction results of protein structure and function by different methods}

The Exome Sequencing analysis of the proband exhibited a novel disease-associated mutation in exon 16 of the already known disease-associated SPAST gene, and the in-frame deletion was identified in the

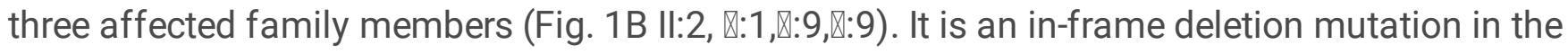
heterozygous state: the GAA nucleotides deletion at codon 1710-1712 position and the circled nucleotide represents the codon 1710 position, where the mutation starts. (Fig. 1B II:2, 邓:1, 邓:9,®:9). According to Human Gene Mutation Database (HGMDpro), the pathogenic mutation site c.1710_1712delGAA has not been reported until now. Therefore, it is a novel mutation. And there are no mutations were identified when 
analysis of other genes associated with HSP was performed: PLP1, L1CAM, SPG11, SPG7, ATL 1 and so on . While the rest asymptomatic family members had no mutations at this site (Fig.1B \:5).

As highlighted in Figure1B, the results of RaptorX prediction showed that this new-found mutation we reported resulted in the synthesis of misfolded protein(Fig.2B) in comparison to native one (Fig.2A).We performed a protein sequence alignment across species showing the area of this in-frame amino acid deletion and the surrounding residues(https://www.uniprot.org/align/A20200502216DA2B77BFBD2E6699CA9B6D1C41EB2087CC00). The result revealed that the spastin protein sequence across species is highly conserved at the position 570 of the protein(red frame) (Fig.2C). Therefore, the lysine deficiency at the position 570 of the protein has a significant impact on the function. Additionally, the result of PROVEAN demonstrated that the mutation site c.1710_1712delGAA has an functional impact on the SPAST protein sequence variations. Given a list of genomic coordinates and variants $(2,32372308, A G A A, A)$, the amino acid change(p.K570del) can be quickly determined and PROVEAN score is computed to be -11.55 , which is significantly lower than the score threshold (cutoff $=-2.5$ ). The deletion variant was predicted as deleterious (Table 2). According to American College of Medical Genetics and Genomics (ACMG) criteria[18], we score this variant as likely pathogenic PM1, PM2, PM4, PP3

\section{Discussion}

According to the family history, accurate description of the clinical phenotype as well as cerebral and spinal MRI, we diagnosed the proband with HSP. Analyses of the Exome Sequencing revealed a novel disease-associated in-frame deletion in the SPAST gene. This mutation consists of three nucleotides deletions (c.1710_1712delGAA) within the exon 16. The onset age of patients in this family is highly variable, which is accordance with the previous study[19]. However, the onset age of affected individuals in our study is obviously earlier than previous studies[20], which promotes us to consider the existence of the new mutation site c.1710_1712delGAA. Additionally, affected individuals in our study presented clinical features of the pHSP, which is consistent with Orlacchio A's study[21].

The SPAST gene has 17 coding exons and encodes the protein spastin, a member of the AAA ATPase protein family. The protein spastin contains two main structural domains: the microtubule interacting and trafficking (MIT) domain in the $\mathrm{N}$ - terminus and the catalytic AAA domain at the $\mathrm{C}$-terminus, in which the former mainly regulates microtubule organization and the later focus on ATPase activity associated with various cellular activities[22]. The two main domains are both essential to accomplish the main known function of spastin: microtubule (MT) severing[23]. More than 200 different mutations located in sites within the AAA region have been identified in patients with HSP-SPG4[24]. Therefore, it is believed that some mutated spastins may result in insufficient microtubule-severing activity by dominant-negative fashion. Additionally, another prevalent hypothesis is neurotoxicity of mutant spastin proteins. The SPAST gene presents two translation initiation codons, which allows to synthesis two spastin isoforms: a full-length isoform called M1(616 amino acid) and a slightly shorter isoform called M87(530 amino acid) 
that lacks the first 87 amino acid[25]. Studies on rodents show that M87 is more abundant in various tissues, whereas M1 is only appreciably detected in brain and spinal cord[26]. Besides that, axonal transport and neurite growth are not affected by the mutated M87[27]. However, Mutant spastin proteins can form defective heterohexamers with wild-type (WT) spastin, and simultaneously produce toxic effect when presented as the tissue-specific M1 isoform[28, 29]. Even though M87 likely harbors the same AAA mutations as the M1 isoform, it is somehow degraded more effectively than mutated M1 in a dominantnegative scenario[30], thus possessing a lower toxicity.

\section{Conclusion}

In Our study, a novel mutation in SPAST gene was found in a Chinese family with multiple affected family members, which significantly enrich the mutation spectrum of HSP. This novel mutation has been inherited at least four generations according to the related investigation, further emphasizing the closed interaction between the phenotypic and genetic heterogeneity of HSP. However, some shortcomings are still existed. For example, we haven't performed functional laboratory studies about the novel mutation due to the unavailable patient cell lines and the related verification on which one molecular mechanisms above of SPAST gene mutants in our study cannot be realized. Haploinsufficiency is the prevalent mechanism at present. Using the haploinsufficiency model of HSP-SPG4 with a 50\% decrease in active spastin levels has shown a lower MT severing[31, 32]. Another hypothesis is mainly that mutated spastin can form defective heterohexamers with wild-type (WT) spastin, and exert a dominant-negative effect. However, there is still considerable debate about the latter one hypothesis. It is unclear whether the mutant M87 can effectively impair the enzymatic activity of WT spastin[33]. Thus, further study should ascertain the role of causative genes to help better understand the relationship between genotypes and phenotypes.

\section{Abbreviations}

hereditary spastic paraplegia(HSP); spastic paraplegia genes (SPG); computed tomography(CT); magnetic resonance imaging(MRI); Sequence Control Software (SCS); Next Generation Sequence (NGS); Human Gene Mutation Database (HGMDpro); microtubule interacting and trafficking (MIT); microtubule (MT); wild- type (WT); reticulum membrane(ER); casein kinase 2(CK2); fast axonal transport(FAT)هProtein Variation Effect Analyzer (PROVEAN); American College of Medical Genetics and Genomics (ACMG); polymerase chain reaction (PCR); room temperature (RT)

\section{Declarations}

\section{Ethics approval and consent to participate}

The study was conducted in accordance with the Declaration of Helsinki and the Ethics Committee of Peking University First Hospital (PKUFH-2019-181). Written informed consents were obtained from all of 
the participants of this family in the study. The written informed consent of the boy aged eleven years in our study was obtained from his parents.

\section{Consent to publish}

Written informed consent was obtained from all of the participants in the study to publish the clinical details and any accompanying clinical images in medical journals. The written informed consent to publish of the boy aged eleven years in our study was obtained from his parents.

\section{Availability of data and material}

The datasets generated and/or analyzed during the current study are already presented in this study. More detail are available from the corresponding author on reasonable request.

\section{Competing Interests}

The authors have no conflict of interests.

\section{Funding}

No grant was provided for this analysis and this study.

\section{Authors' contributions}

YN H and WW Y designed the work and analyzed the clinical data. HQ J and JW D performed the neurologic examination and interpreted the clinical data related to the HSP. D N collected the material of these family members and analyzed the genetic data. WW Y was a major contributor to writing the manuscript. All authors contributed toward drafting and critically revising the paper, gave final approval of the version to be published.

\section{Acknowledgements}

We would like to thank all members of the family participating in the study for agreeing to publish their available clinical data in medical journals.

\section{References}

1. Depienne C, Stevanin G, Brice A, Durr A: Hereditary spastic paraplegias: an update. Curr Opin Neurol 2007, 20(6):674-680.

2. Esteves T, Durr A, Mundwiller E, Loureiro JL, Boutry M, Gonzalez MA, Gauthier J, El-Hachimi KH, Depienne C, Muriel MP et al: Loss of association of REEP2 with membranes leads to hereditary spastic paraplegia. Am J Hum Genet 2014, 94(2):268-277.

3. Lo Giudice T, Lombardi F, Santorelli FM, Kawarai T, Orlacchio A: Hereditary spastic paraplegia: clinical-genetic characteristics and evolving molecular mechanisms. Experimental neurology 2014, 261:518-539. 
4. Harding AE: Classification of the hereditary ataxias and paraplegias. Lancet (London, England) 1983, 1(8334):1151-1155.

5. Proukakis C, Moore D, Labrum R, Wood NW, Houlden H: Detection of novel mutations and review of published data suggests that hereditary spastic paraplegia caused by spastin (SPAST) mutations is found more often in males. J Neurol Sci 2011, 306(1-2):62-65.

6. Finsterer J, Loscher W, Quasthoff S, Wanschitz J, Auer-Grumbach M, Stevanin G: Hereditary spastic paraplegias with autosomal dominant, recessive, X-linked, or maternal trait of inheritance. $J$ Neurol Sci 2012, 318(1-2):1-18.

7. Fei QZ, Tang WG, Rong TY, Tang HD, Liu JR, Guo ZL, Fu Y, Xiao Q, Wang XJ, He SB et al: Two novel mutations in the Spastin gene of Chinese patients with hereditary spastic paraplegia. Eur $\mathrm{J}$ Neurol 2011, 18(9):1194-1196.

8. Parodi L, Fenu S, Stevanin G, Durr A: Hereditary spastic paraplegia: More than an upper motor neuron disease. Rev Neurol (Paris) 2017, 173(5):352-360.

9. Hentati A, Pericak-Vance MA, Lennon F, Wasserman B, Hentati F, Juneja T, Angrist MH, Hung WY, Boustany RM, Bohlega $S$ et al: Linkage of a locus for autosomal dominant familial spastic paraplegia to chromosome 2p markers. Hum Mol Genet 1994, 3(10):1867-1871.

10. de Bot ST, van den Elzen RT, Mensenkamp AR, Schelhaas HJ, Willemsen MA, Knoers NV, Kremer HP, van de Warrenburg BP, Scheffer H: Hereditary spastic paraplegia due to SPAST mutations in 151 Dutch patients: new clinical aspects and 27 novel mutations. J Neurol Neurosurg Psychiatry 2010, 81(10):1073-1078.

11. Erichsen AK, Inderhaug E, Mattingsdal M, Eiklid K, Tallaksen CM: Seven novel mutations and four exon deletions in a collection of Norwegian patients with SPG4 hereditary spastic paraplegia. Eur J Neurol 2007, 14(7):809-814.

12. de Bot ST, van de Warrenburg BP, Kremer HP, Willemsen MA: Child neurology: hereditary spastic paraplegia in children. Neurology 2010, 75(19):e75-79.

13. W Y, H J, Q Y, D N, Y H: A novel PDCD10 gene mutation in cerebral cavernous malformations: a case report and review of the literature. Journal of pain research 2019, 12:1127-1132.

14. Ling X, Zhao D-h, Zhao J, Shen B, Yang X: Episodic ataxia type 2 characterised by recurrent dizziness/vertigo: a report of four cases. International Journal of Neuroscience 2019, 129(2):103109.

15. Scimone C, Donato L, Esposito T, Rinaldi C, D'Angelo R, Sidoti A: A novel RLBP1 gene geographical area-related mutation present in a young patient with retinitis punctata albescens. Hum Genomics 2017, 11(1):18.

16. Choi Y, Chan AP: PROVEAN web server: a tool to predict the functional effect of amino acid substitutions and indels. Bioinformatics 2015, 31(16):2745-2747.

17. McDermott CJ, Burness CE, Kirby J, Cox LE, Rao DG, Hewamadduma C, Sharrack B, Hadjivassiliou M, Chinnery PF, Dalton A et al: Clinical features of hereditary spastic paraplegia due to spastin mutation. Neurology 2006, 67(1):45-51. 
18. Richards S, Aziz N, Bale S, Bick D, Das S, Gastier-Foster J, Grody WW, Hegde M, Lyon E, Spector E et al: Standards and guidelines for the interpretation of sequence variants: a joint consensus recommendation of the American College of Medical Genetics and Genomics and the Association for Molecular Pathology. Genet Med 2015, 17(5):405-424.

19. Durr A, Davoine CS, Paternotte C, von Fellenberg J, Cogilinicean S, Coutinho P, Lamy C, Bourgeois S, Prud'homme JF, Penet C et al: Phenotype of autosomal dominant spastic paraplegia linked to chromosome 2. Brain : a journal of neurology 1996, 119 (Pt 5):1487-1496.

20. Orlacchio A, Kawarai T, Gaudiello F, Totaro A, Schillaci O, Stefani A, Floris R, St George-Hyslop PH, Sorbi S, Bernardi G: Clinical and genetic study of a large SPG4 Italian family. Mov Disord 2005, 20(8):1055-1059.

21. Orlacchio A, Patrono C, Borreca A, Babalini C, Bernardi G, Kawarai T: Spastic paraplegia in Romania: high prevalence of SPG4 mutations. J Neurol Neurosurg Psychiatry 2008, 79(5):606-607.

22. Salinas S, Carazo-Salas RE, Proukakis C, Schiavo G, Warner TT: Spastin and microtubules: Functions in health and disease. Journal of neuroscience research 2007, 85(12):2778-2782.

23. White SR, Evans KJ, Lary J, Cole JL, Lauring B: Recognition of C-terminal amino acids in tubulin by pore loops in Spastin is important for microtubule severing. J Cell Biol 2007, 176(7):995-1005.

24. Shoukier M, Neesen J, Sauter SM, Argyriou L, Doerwald N, Pantakani DV, Mannan AU: Expansion of mutation spectrum, determination of mutation cluster regions and predictive structural classification of SPAST mutations in hereditary spastic paraplegia. Eur J Hum Genet 2009, 17(2):187-194.

25. Claudiani P, Riano E, Errico A, Andolfi G, Rugarli El: Spastin subcellular localization is regulated through usage of different translation start sites and active export from the nucleus. Exp Cell Res 2005, 309(2):358-369.

26. Solowska JM, Morfini G, Falnikar A, Himes BT, Brady ST, Huang D, Baas PW: Quantitative and functional analyses of spastin in the nervous system: implications for hereditary spastic paraplegia. The Journal of neuroscience : the official journal of the Society for Neuroscience 2008, 28(9):21472157.

27. Solowska JM, D'Rozario M, Jean DC, Davidson MW, Marenda DR, Baas PW: Pathogenic mutation of spastin has gain-of-function effects on microtubule dynamics. The Journal of neuroscience : the official journal of the Society for Neuroscience 2014, 34(5):1856-1867.

28. Eckert T, Le DT, Link S, Friedmann L, Woehlke G: Spastin's microtubule-binding properties and comparison to katanin. PLoS One 2012, 7(12):e50161.

29. Le DT, Eckert T, Woehlke G: Computer simulation of assembly and co-operativity of hexameric AAA ATPases. PLoS One 2013, 8(7):e67815.

30. Solowska JM, Garbern JY, Baas PW: Evaluation of loss of function as an explanation for SPG4based hereditary spastic paraplegia. Hum Mol Genet 2010, 19(14):2767-2779.

31. Burger J, Fonknechten N, Hoeltzenbein M, Neumann L, Bratanoff E, Hazan J, Reis A: Hereditary spastic paraplegia caused by mutations in the SPG4 gene. Eur J Hum Genet 2000, 8(10):771-776. 
32. Fonknechten N, Mavel D, Byrne P, Davoine CS, Cruaud C, Bonsch D, Samson D, Coutinho P, Hutchinson M, McMonagle P et al: Spectrum of SPG4 mutations in autosomal dominant spastic paraplegia. Hum Mol Genet 2000, 9(4):637-644.

33. Solowska JM, Baas PW: Hereditary spastic paraplegia SPG4: what is known and not known about the disease. Brain : a journal of neurology 2015, 138(Pt 9):2471-2484.

\section{Tables}

Table 1: Clinical features of the affected individuals within the family.

\begin{tabular}{lllll}
\hline Individual ID & II: 6 & III: 1 & III:9 & IV:9 \\
\hline Sex & F & M & F & M \\
Age at onset(years) & early $30 \mathrm{~s}$ & early $10 \mathrm{~s}$ & early $10 \mathrm{~s}$ & 3 \\
Age at examination(years) & 63 & 46 & 32 & 10 \\
Disease duration(years) & $>33$ & $>36$ & $>22$ & 7 \\
Disability score & 4 & 2 & 2 & 2 \\
Lower limb hyperreflexia & + & + & + & + \\
Lower limb spasticity & + & + & - & + \\
Lower limb pyramidal weakness & - & - & + & + \\
Babinski sign & + & + & + & + \\
Upper limb hyperreflexia & + & + & + & - \\
Upper limb spasticity & - & - & + & - \\
Sphincter disturbances & + & + & - & - \\
Scoliosis & - & - & - & - \\
Pes cavus & + & - & Pulmonary & Reflux at mitral \\
Sensory deficits & + & - & hypertension & and tricuspid valve \\
Mental retardation & - & - & & + \\
concomitant diseases & - & & & +
\end{tabular}

+ indicates the presence of a feature, - indicates the absence of a feature, respectively.

a: Age at onset was calculated approximately when appeared to have difficulty in walking first.

b: Disability stages: 1: normal, 2: able to walk alone but not run, $3:$ need the help of a walking aid or support, 4 : wheelchair user

Table 2: The genome variants results are represented as PROVEAN scores and predictions.

\begin{tabular}{ccccccccc}
\hline INPUT & PROTEIN_ID & LEN & CODON_CHANGE & POS & $\begin{array}{c}\text { RESIDUE } \\
\text { REF }\end{array}$ & $\begin{array}{c}\text { TYPE } \\
\text { STH }\end{array}$ & $\begin{array}{c}\text { SCORE } \\
\begin{array}{c}\text { PREDICTION } \\
\text { (cutoff=-2.5) }\end{array}\end{array}$ \\
\hline 2,32372308, AGAA,A & ENSP00000320885 & 616 & GTG A[AGAA/A]T ATG & 570 & $\mathrm{~K}$ & Deletion & -11.55 & Deleterious \\
\hline
\end{tabular}

\section{Figures}


A

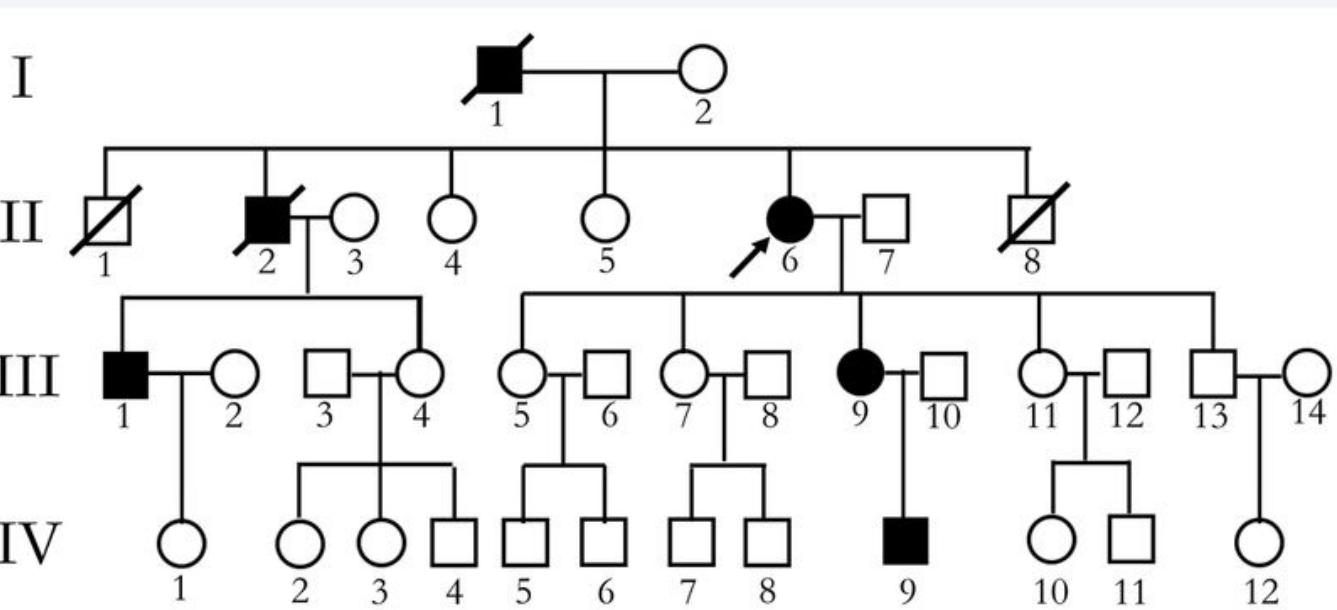

B

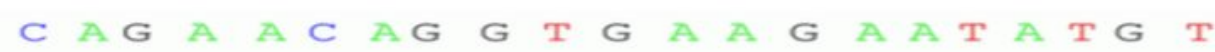

III:5

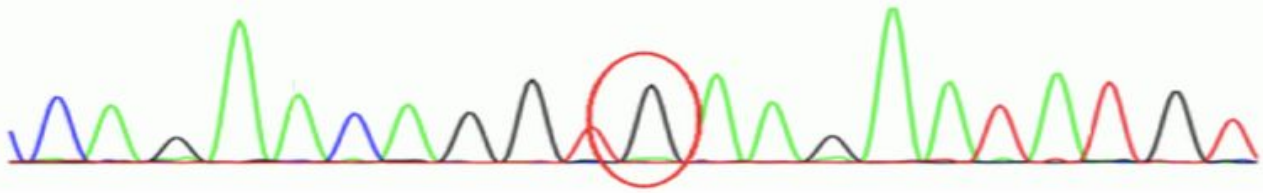

II:6
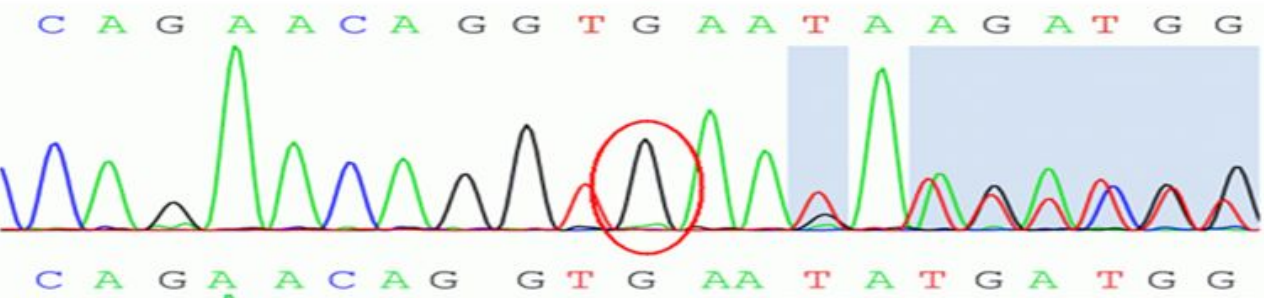

III:1

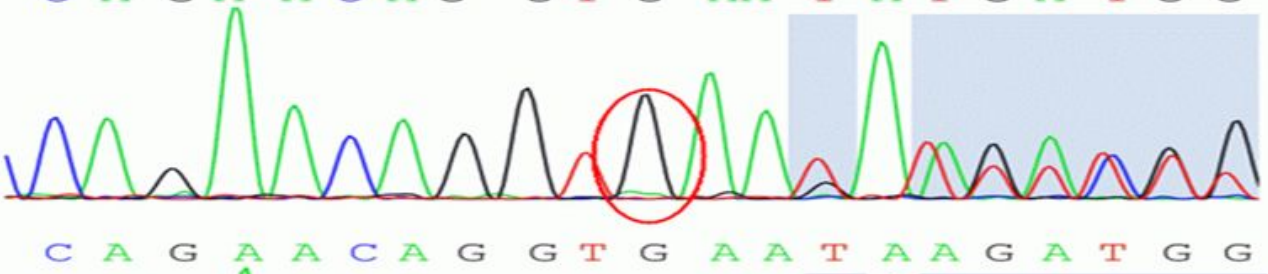

III:9

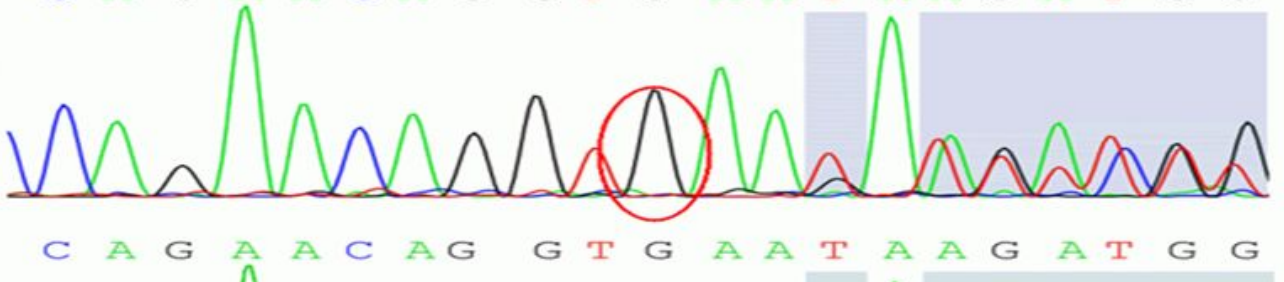

IV:9

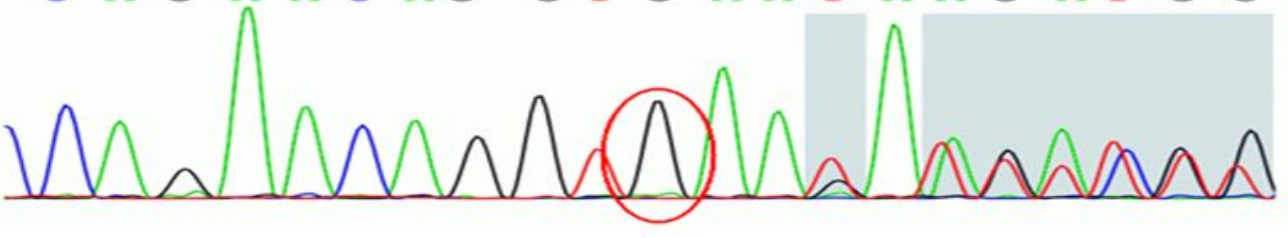

\section{Figure 1}

Pedigree of the investigated HSP family harbouring a novel SPAST gene mutation. A: The black arrow indicates the proband II:6. Squares indicate male, circles indicate females. Individuals affected with HSP are represented by black filled, while Healthy members are indicated by empty symbols. slashes indicate already dead. B: Detection of the mutation of SPAST gene in a Chinese family. Sequence analysis revealed a newly identified in-frame deletion mutation in a heterozygous form in four affected 


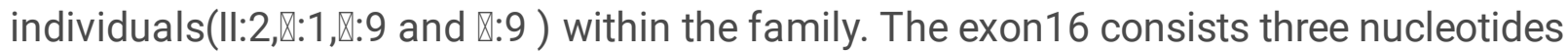
deletion(c.1710_1712delGAA). $₫: 5$ is the representative wild type sequences of the investigated healthy family members

A

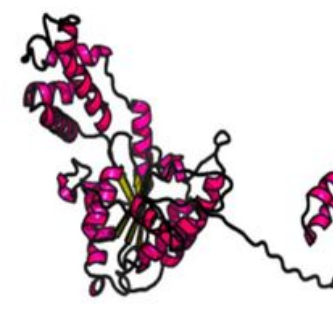

C

$\begin{array}{ll}\text { Q9UBP0 } & \text { SPAST_HUMAN } \\ \text { A2VDN5 } & \text { SPAST_BOVIN } \\ \text { Q9QYY8 } & \text { SPAST_MOUSE } \\ \text { B2RYN7 } & \text { SPAST_RAT } \\ \text { Q719N1 } & \text { SPAST_-PIG } \\ \text { Q05AS3 } & \text { SPAST_XENTR } \\ \text { Q6NW58 } & \text { SPAST_DANRE } \\ \text { Q6AZT2 } & \text { SPAST_XENLA }\end{array}$

$\mathrm{B}$

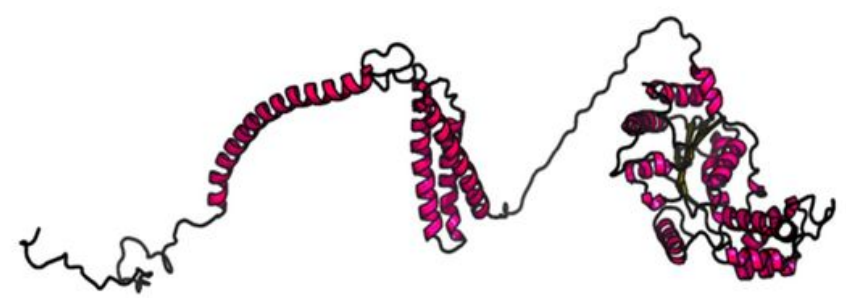

534

\section{2}

\section{2}

499

\section{4}

521

487

518

\begin{abstract}
LAQLARMTDGYSGSDLTALAKDAALGPIRELKPEQVKNMSASEMRNIRLSDFTESLKKIK 593 LAQLARMTNGYSGSDLTALAKDAALGPIRELKPEQVKNMSASEMRNIRLSDFTESLKKIK LAQLARMTDGYSGSDLTALAKDAALGPIRELKPEQVKNMSASEMRNIRLSDFTESLKKIK LAQLARMTDGYSGSDLTALAKDAALGPIRELKPEQVKNMSASEMRNIRLSDFTESLKKIK LAQLARLTDGYSGSDLTALAKDAALGPIRELKPEQVKNMSASEMRNIRLSDFTESLKKIK 593 LTQLSRLTEGYSGSDITALAKDAALGPIRELKPEQVWNMAASEMRNIKYSDFLSSLKKIK $\quad 580$ LSQLARLTDGYSGSDLTSLAKDAALGPIRELKPEQV NMSAHEMRDIRISDFLESLKRIK 546 LTQLSRLTEGYSGSDITALAKDAALGPIRELKPEQVWNMAASEMRNMKYSDFLGSLKKIK 577
\end{abstract}

Figure 2

Tertiary structure alteration prediction of SPAST by RaptorX tool. A. The tertiary structure of native protein. B. Tertiary structure of p.K570del affected protein. The novel mutation we reported resulted in the synthesis of misfolded protein. $\mathrm{C}$. The spastin protein sequence alignment across species showing the area of this in-frame amino acid deletion (red frame) and the surrounding residues 